\title{
Consumo alimentar de atletas: reflexões sobre recomendações nutricionais, hábitos alimentares e métodos para avaliação do gasto e consumo energéticos
}

\author{
Athletes' food intake: reflections on nutritional recommendations, \\ food habits and methods \\ for assessing energy expenditure and energy intake
}

Vilma Pereira PANZA'

Mara Sérgia Pacheco Honório COELHO'

Patrícia Faria Di PIETRO'

Maria Alice Altenburg de ASSIS 1

Francisco de Assis Guedes de VASCONCELOS

\section{RES U M O}

O objetivo do artigo foi efetuar revisão sobre o consumo alimentar de atletas, enfatizando recomendações nutricionais, adequações dietéticas, comportamento alimentar e limitações dos métodos na avaliação dietética e estimativa do gasto energético nesta população. Foram analisados 30 artigos, publicados no período de 1984-2004, selecionados em bases eletrônicas de dados. O critério de inclusão dos artigos foi a abordagem sobre aspectos nutricionais relacionados ao exercício, recomendações de energia e nutrientes, bem como consumo alimentar de atletas. As recomendações de energia, macronutrientes e hidratação para atletas já estão bem determinadas, porém, pouco se conhece sobre as necessidades de vitaminas e minerais. Contudo, existe um consenso de que as necessidades de micronutrientes para a maioria desses indivíduos podem ser atendidas por uma dieta variada e equilibrada. Por outro lado, estudos indicam que a inadequação de energia e nutrientes ainda predomina em vários grupos atléticos, revelando a necessidade da reeducação nutricional. Diversos fatores inerentes à modalidade esportiva, tais como os esquemas de treinamento e as exigências relativas à imagem corporal, podem influenciar os hábitos alimentares do atleta. Portanto, a compreensão das relações entre o padrão de alimentação de atletas e os diversos fatores relacionados ao esporte são aspectos fundamentais para o estabelecimento de orientações nutricionais. A ocorrência de erros sistemáticos em pesquisas com atletas que empregam métodos que utilizam o auto-relato, ressalta a importância do rigor metodológico na aplicação desses instrumentos.

Termos de indexação: atletas; consumo de alimentos; recomendações nutricionais; treinamento.

\footnotetext{
1 Universidade Federal de Santa Catarina, Programa de Pós-Graduação em Nutrição. Campus Universitário, 88040-970, Trindade, Florianópolis, SC, Brasil. Correspondência para/Correspondence to: V.P. PANZA. E-mail:<giovil@terra.com.br>
} 


\section{A B S T R A C T}

The purpose of this paper was to review the bibliography on athletes' food intake, emphasizing nutritional recommendations, dietary propriety and behavior, limitations of the methods for assessing food intake and estimated energy expenditure in this population. Thirty articles were analyzed, published from 1984 to 2004 , selected from electronic databases. Articles that discussed nutritional aspects associated with exercise and those that made recommendations regarding energy, nutrient or food intake were included. Determinations for energy, macronutrient and liquid intake for athletes are already well established but little is known about their need of vitamins and minerals. However, there is a consensus that the micronutrient requirements for most of these individuals can be met by a varied and balanced diet. On the other hand, studies show that unbalanced energy and nutrient intakes still prevail among many athletic groups, revealing the need for dietary education. Many factors related to the type of sport such as training schemes and body image requirements may influence the athletes' dietary habits. Therefore, understanding the relationship between the athletes' eating patterns and the various patterns associated with the sport in question is essential to establish specific nutritional guidance. The occurrence of systematic errors in researches involving athletes that employ methods that rely on self reports emphasizes the importance of following a strict methodology when using these instruments.

Indexing terms: athletic; food consumption; nutrition policy; training.

\section{N T R O D U Ç Ã O}

A prática de atividades esportivas pode proporcionar benefícios à composição corporal, à saúde e à qualidade de vida ${ }^{1}$. No entanto, o esporte competitivo nem sempre representa sinônimo de equilíbrio no organismo. As alterações fisiológicas e os desgastes nutricionais gerados pelo esforço físico podem conduzir o atleta ao limiar da saúde e da doença, se não houver a compensação adequada desses eventos ${ }^{2-4}$. Contudo, a magnitude das respostas ao exercício parece estar associada à interação de diferentes variáveis, como a natureza do estímulo, a duração e intensidade do esforço, o grau de treinamento e o estado nutricional do indivíduo $0^{1,3}$.

A importância da nutrição na performance e saúde de atletas já se encontra suficientemente documentada na literatura ${ }^{1-3}$. Diversos trabalhos têm buscado estabelecer recomendações relativas ao consumo nutricional e estratégias dietéticas que possam otimizar o desempenho e atenuar o impacto negativo do exercício na saúde ${ }^{1,4}$. Junto a isso, nas últimas décadas, várias pesquisas avaliaram, em diferentes grupos atléticos, o quanto a prática alimentar desses indivíduos tem refletido os conhecimentos científicos acumulados na área da nutrição esportiva ${ }^{5-7}$.
A maioria dos estudos dietéticos procura examinar o consumo alimentar de atletas, apenas para avaliar a adequação entre as recomendações nutricionais e os padrões dietéticos ${ }^{5}$. Pouco interesse é destinado à investigação das razões que levam à escolha dietética desses indivíduos. Estudos mais recentes têm direcionado seu foco para o entendimento das relações entre o padrão de consumo alimentar em populações atléticas e os variados aspectos inerentes ao grupo, dentro e fora da prática esportiva ${ }^{8-10}$. Esse tipo de abordagem, em pesquisas de consumo alimentar de atletas, confere grande contribuição no estabelecimento de orientações nutricionais específicas que possam auxiliar na melhora do desempenho físico e na manutenção da saúde do indivíduo 5.8 .

O objetivo deste artigo foi descrever a prática alimentar de atletas de diferentes modalidades esportivas frente às recomendações nutricionais, a partir de uma revisão da literatura pertinente. Apresentam-se as características do comportamento alimentar e da ingestão dietética e identificam-se as limitações associadas às metodologias empregadas para estimar o consumo e o gasto energéticos de atletas de diferentes modalidades esportivas. 


\section{R E C O M E N D A Ç Õ ES NUTRICIONAIS}

O estabelecimento de recomendações nutricionais específicas para atletas ${ }^{1}$, representa a disponibilização de um importante instrumento teórico para o planejamento dietético destinado a esta população. A adequação do consumo energético e nutricional é essencial para a manutenção da performance, da composição corporal e da saúde desses indivíduos ${ }^{1,3}$. A baixa ingestão de energia pode resultar em fornecimento insuficiente de importantes nutrientes relacionados ao metabolismo energético, à reparação tecidual, ao sistema antioxidante e à resposta imunológica' ${ }^{1}$.

$O$ déficit energético em atletas tem sido associado a alterações metabólicas e reprodutivas relacionadas ao exercício ${ }^{1,3}$. A ocorrência de amenorréia em mulheres atletas está associada a marcantes reduções no consumo de energia e lipídeos e nas concentrações sangüíneas de leptina, estrogênio, hormônios da tireóide e insulina ${ }^{3}$. A estimativa do dispêndio energético de atletas é baseada no gasto metabólico basal e no tipo, intensidade, duração e freqüência do exercício'. De uma forma geral, é recomendado que atletas homens e mulheres que se exercitam por mais de 90 minutos por dia, tenham uma ingestão energética acima de $50 \mathrm{kcal} / \mathrm{kg}$ e $45-50 \mathrm{kcal} / \mathrm{kg}$, respectivamente ${ }^{11}$.

O consumo apropriado de carboidrato é fundamental para a otimização dos estoques iniciais de glicogênio muscular, a manutenção dos níveis de glicose sangüínea durante o exercício e a adequada reposição das reservas de glicogênio na fase de recuperação ${ }^{1}$. Além disso, a ingestão de carboidrato pode atenuar as alterações negativas no sistema imune devido ao exercício ${ }^{4}$. Existem evidências de que o consumo de dieta rica em carboidrato, em período de treinamento intenso, pode favorecer não somente o desempenho como o estado de humor do atleta ${ }^{12}$. As recomendações de carboidrato para atletas são de $6-10 \mathrm{~g} / \mathrm{kg}$ de peso corporal por dia ou $60-70 \% \mathrm{da}$ ingestão energética diária ${ }^{1,13}$; entretanto, a necessidade individual dependerá do gasto energético, da modalidade esportiva, do sexo e das condições ambientais ${ }^{1}$

O reparo e crescimento muscular e a relativa contribuição no metabolismo energético são exemplos que confirmam a relevância do adequado consumo protéico para indivíduos envolvidos em treinamento físico diário ${ }^{14}$. As recomendações da ingestão diária de proteínas para atletas consistem em 1,2-1,7g/kg de peso corporal ou $12 \%-15 \%$ do consumo energético total ${ }^{1,13}$. Em recente estudo, Tarnopolsky ${ }^{14}$ concluiu que atletas de endurance (resistência) envolvidos em treinamento de moderada intensidade necessitam de uma ingestão protéica de $1,1 \mathrm{~g} / \mathrm{kg} / \mathrm{dia}$, enquanto atletas de endurance de elite podem requerer até $1,6 \mathrm{~g} / \mathrm{kg} / \mathrm{dia}$. Por outro lado, atletas de força podem necessitar de 1,6-1,7g de proteína por quilograma de peso corporal por dia ${ }^{15}$.

Os lipídios participam de diversos processos celulares de especial importância para atletas, como o fornecimento de energia para os músculos em exercício, a síntese de hormônios esteróides e a modulação da resposta inflamatória',16,17. As recomendações de lipídeos para atletas são de 20\%-25\% da ingestão energética diária'. A utilização de gordura como fonte de energia adicional à dieta pode ser adotada, devendo, porém, alcançar, no máximo, 30\% do valor energético total (VET). Por outro lado, um consumo lipídico inferior a $15 \%$ do VET parece não trazer qualquer benefício à saúde e à performance. Sugere-se que as proporções da energia dietética oriunda de gorduras sigam as recomendações para a população em geral ${ }^{1}$. Embora as recomendações de proporções energéticas dos macronutrientes sejam destinadas à população atlética em geral, especialistas sugerem que essas recomendações devam ser interpretadas com certa cautela. Em uma dieta de $2000 \mathrm{kcal}$ por exemplo, a recomendação de $60 \%$ de carboidrato a uma atleta de $60 \mathrm{~kg}$ pode representar um fornecimento de carboidrato insuficiente (apenas $4-5 \mathrm{~g} / \mathrm{kg}$ ) para proporcionar adequada reserva de glicogênio muscular ${ }^{1}$. 
As vitaminas e minerais participam de processos celulares relacionados ao metabolismo energético; contração, reparação e crescimento muscular; defesa antioxidante e resposta imune ${ }^{1,2}$ Contudo, tanto o exercício agudo como o treinamento, podem levar a alterações no metabolismo, na distribuição e na excreção de vitaminas e minerais ${ }^{1,2}$. Em vista disso, as necessidades de micronutrientes específicos podem ser afetadas conforme as demandas fisiológicas, em resposta ao esforçO². Alguns autores supõem que atletas possam apresentar as necessidades relativas a determinados tipos de micronutrientes acima da Recommended Dietary Allowance (RDA) ${ }^{13,18-19}$. Entretanto, com a divulgação das Dietary Reference Intakes (DRIs) e o estabelecimento do nível superior tolerável de ingestão (UL) para vários micronutrientes ${ }^{20}$, essa questão deve ser vista com bastante cautela. Além disso, segundo recente posicionamento de entidades científicas, direcionado à nutrição e à performance atlética', o consumo de dieta variada e balanceada parece atender o incremento nas necessidades de micronutrientes gerado pelo treinamento.

A realização de exercícios, principalmente os intensos ou os realizados em ambientes quentes, implica em maior liberação de calor corporal, pela produção de suor, um dos principais mecanismos fisiológicos da termorregulação ${ }^{21}$. Portanto, o atleta deve ingerir líquido antes, durante e após o exercício, a fim de equilibrar as perdas hídricas decorrentes da sudorese excessiva. Recomenda-se que 400-600mL de líquidos sejam consumidos antes do exercício. Durante o esforço, a ingestão de líquidos deve incluir 150-350mL a cada 15-20 minutos. Para a reposição das perdas hídricas no período de recuperação, o atleta deve consumir, pelo menos, $450-675 \mathrm{~mL}$ de líquidos a cada $0,5 \mathrm{~kg}$ de peso corporal perdido durante o exercício’.

\section{PADRÕES E HÁ BITOS ALIMENTARES}

As demandas dos treinamentos e competições, junto a outras atividades rotineiras do atleta, como estudo ou trabalho, podem exercer grande influência nos seus hábitos alimentares ${ }^{10}$. Nesse sentido, devem ser observados vários aspectos inerentes à rotina esportiva como o tipo, a intensidade e a duração do exercício; a tolerância à prática alimentar durante o esforço; os possíveis locais para reabastecimento durante os exercícios externos prolongados; a necessidade de controle de peso corporal e outros ${ }^{5-7}$. Assim, o conhecimento do padrão de treinamento e estilo de vida do atleta permite identificar e contornar quais fatores podem limitar o seu consumo dietético. Conforme recomendam Ziegler et al. ${ }^{10}$, por exemplo, a ingestão de pequenas e freqüentes refeições de adequada densidade de energia e nutrientes, pode auxiliar o atleta no atendimento de suas necessidades nutricionais, e ao mesmo tempo, prevenir distúrbios gastrintestinais durante o exercício, impedir a ingestão excessiva de alimentos e evitar a fadiga.

A importância dada às questões nutricionais no desempenho esportivo também pode determinar o comportamento alimentar de grupos atléticos. Burke et al. ${ }^{5}$ identificaram padrões dietéticos próprios ao tipo de modalidade esportiva, ao comparar quatro grupos de atletas de elite do sexo masculino (triatletas, maratonistas, levantadores de peso e jogadores de futebol). Os atletas de endurance (triatletas e maratonistas) apresentaram maiores ingestões de energia e de carboidrato do que os demais grupos, o que foi explicado pelo alto consumo de pães e cereais e pelo maior dispêndio energético nos treinos. Além disso, esses atletas foram os que se mostraram mais conscientes da importância da alimentação na saúde e no desempenho, e mais interessados no preparo de suas refeições e em leituras relativas à nutrição. Por outro lado, os jogadores de futebol apresentaram maiores consumo de álcool e gordura e foram os que demonstraram menor interesse quanto aos benefícios da alimentação para a performance. Para esse grupo, um grande consumo de álcool, após as partidas, era sinônimo de relaxamento, bravura e união entre os membros da equipe. 
O Anexo apresenta uma síntese descritiva dos estudos selecionados que investigaram o consumo dietético de atletas ${ }^{22-28}$. A grande procura por práticas dietéticas que possam otimizar o rendimento esportivo tem levado a um maior interesse pela utilização de suplementos nutricionais do que por condutas alimentares ajustadas aos objetivos do treinamento 5,9,29. Paschoal \& Amâncio $^{9}$ verificaram um elevado consumo de suplementos protéicos, tais como aminoácidos isolados, complexos de aminoácidos e creatina, entre nadadores de elite durante o período competitivo. Além disso, a média de ingestão protéica dietética entre esses atletas estava acima das recomendações (Anexo). Contudo, ainda que a média do consumo de carboidrato estivesse dentro do recomendado, a maioria dos atletas apresentava ingestão insuficiente desse nutriente. As ingestões de vitaminas e minerais eram adequadas, exceto para o cálcio, cuja inadequação foi atribuída a um baixo consumo de leite e derivados. Destaca-se que, apesar de os atletas estudados terem demonstrado interesse em melhorar o seu desempenho por meio do uso de suplementos nutricionais, a ingestão dietética de nutrientes fundamentais para a eficiência do trabalho muscular e a manutenção da massa óssea ${ }^{1}$, tais como o carboidrato e o cálcio, foi negligenciada.

Embora haja um consenso de que a ingestão de dieta variada e equilibrada, provavelmente, preencha as necessidades de vitaminas e minerais para os atletas em geral', as necessidades de micronutrientes para atletas de longas distâncias parecem demandar mais investigações. Singh et al. ${ }^{22}$ relataram que suplementos de vitaminas e minerais eram habitualmente utilizados em um grupo de ultramaratonistas de ambos os sexos, o que resultava em uma ingestão diária de micronutrientes acima das recomendações. Vale ressaltar que, embora o consumo total de vitamina $B_{12}$ tenha ultrapassado em 25,65 vezes as recomendações, as concentrações plasmáticas e a excreção urinária desta vitamina nos atletas estudados eram semelhantes às de indivíduos não suplementados e não envolvidos em esportes de endurance, sugerindo uma elevada necessidade deste nutriente para esta modalidade esportiva.

O poder aquisitivo do atleta e os aspectos culturais podem constituir-se em importantes determinantes da qualidade e da quantidade de alimentos consumidos. Examinando o padrão de ingestão alimentar e de macronutrientes de corredores adolescentes quenianos residentes em uma escola secundária, Christensen et al. ${ }^{23}$ observaram que a dieta desses atletas era limitada ao consumo diário de milho e feijão, repolho e couve cozida, café e leite fermentado. A ingestão de carne era restrita a apenas duas vezes na semana. Pão, leite, laranja e refrigerantes eram eventualmente ingeridos entre as refeições. Embora houvesse variedade limitada de alimentos, os corredores estavam em equilíbrio energético e com adequado consumo de carboidrato (Anexo). Apesar de a ingestão protéica desses indivíduos atingir as recomendações para atletas de endurance $e^{1,14}$, o consumo de aminoácidos essenciais estava no limite inferior ao recomendado. Segundo a conclusão dos autores, quando o consumo de macronutrientes é satisfatório, principalmente de carboidratos, as limitações na escolha de alimentos nem sempre interferem negativamente no desempenho atlético.

As exigências relativas à imagem corporal e ao controle de peso parecem desempenhar relevante papel no comportamento alimentar e no padrão dietético de diversos grupos atléticos ${ }^{6-8}$. Vários são os relatos de inadequações nutricionais e desordens alimentares em atletas, notadamente em mulheres envolvidas em modalidades esportivas cujo desempenho esteja estreitamente associado à imagem ou ao peso corporal, tais como a patinação artística e o fisiculturismo ${ }^{6,7}$. Distúrbios de imagem corporal, restrição alimentar e disfunção menstrual dessas atletas parecem agravar-se no período competitivo ${ }^{24}$.

O treinamento de patinação artística de atletas de elite pode envolver a prática de cinco a seis horas de exercícios por dia ${ }^{6}$. Atletas desta modalidade esportiva, tipicamente, devem apre- 
sentar, além de grande habilidade e beleza física, significativa força e resistência aeróbia, aptidões que lhes conferem certas características de atletas de força e endurance ${ }^{30}$. Por outro lado, a necessidade de um baixo peso corporal, para a otimização de complexas manobras, pode conduzir o atleta à inadequação nutricional e ao comprometimento da performance ${ }^{6,30}$

Ziegler et al. ${ }^{6}$ analisaram a dieta de patinadores de elite de ambos os sexos e observaram que as mulheres apresentaram o consumo energético abaixo das recomendações, bem como ingestão insuficiente de folato, cálcio, ferro, magnésio e zinco. Segundo os autores, a severa restrição alimentar das patinadoras poderia estar associada à sua preocupação com a aparência e imagem corporal. Contudo, considerando as recomendações para atletas ${ }^{11}$, e não somente as RDAs, ressalta-se que não só um déficit energético, como também um baixo consumo de carboidratos", ocorreu tanto nas mulheres quanto nos homens (Anexo). Assim, a preocupação com a imagem corporal pareceu se manifestar em ambos os sexos neste grupo estudado. Por outro lado, os patinadores homens apresentaram elevado consumo de gordura total, gordura saturada e colesterol. Conforme deduziram as autoras, o alto consumo lipídico e a ingestão freqüente de fast food e carnes eram, provavelmente, conseqüências dos programas de treinamento e competições e de intensos esquemas de viagens. Padrões de consumo nutricional, semelhantes aos encontrados neste estudo, foram relatados em outros trabalhos com patinadores de elite ${ }^{10,30}$.

A preocupação com o controle de peso parece não ser restrita apenas às modalidades esportivas que enfatizam a imagem e o peso corporal24,25. Embora a prática competitiva de voleibol não esteja tipicamente associada a severo controle de peso corporal, Beals ${ }^{24}$ identificou que jogadoras adolescentes de voleibol praticavam restrição energética, consumiam dieta liquida e limitavam o tipo e a quantidade de alimentos consumidos. Ainda que o sobrepeso não tenha sido identificado, cerca da metade das atletas desejavam perder peso. As principais inadequações nutricionais encontradas neste grupo relacionavam-se ao consumo de energia e carboidrato (Anexo). Além disso, ingestões abaixo das recomendações foram verificadas para folato, ferro, cálcio, magnésio e zinco. Junto às inadequações dietéticas, episódios de disfunções menstruais, passadas ou atuais, como amenorréia, oligomenorréia e irregularidade nos ciclos menstruais particularmente durante $o$ período competitivo, foram relatados por várias das atletas avaliadas.

Mullinix et al. ${ }^{8}$ avaliaram a ingestão dietética de jogadoras de futebol submetidas a regimes de treinamento intenso (três a quatro horas/dia), e observaram um padrão fracionado de consumo de alimentos (quatro a seis refeições/dia). Neste estudo, as análises das dietas revelaram ingestões inadequadas de energia total, carboidratos (Anexo) e alguns micronutrientes, sugerindo a necessidade da inclusão de alimentos de maior densidade energética e nutricional. As vitaminas D e E, folato, zinco, cálcio, fósforo e magnésio dietéticos eram consumidos em quantidades inferiores às recomendadas. Todavia, a utilização de suplementos de vitaminas e minerais era freqüente entre as jogadoras estudadas. Ainda que o grupo avaliado tenha demonstrado percepções positivas do condicionamento físico e da imagem corporal, a prática de métodos de controle de peso corporal foi relatada por algumas das atletas. Entre os métodos mais comuns estavam exercícios além do treinamento habitual, omissão de refeições, dietas hiperprotéicas/hipoglicídicas, orientação nutricional com profissional de saúde e dietas líquidas.

Portanto, a pressão para a manutenção de um baixo peso corporal pode estar, muitas vezes, associada ao desejo da própria atleta em manter ou melhorar sua auto-imagem. No entanto, a ausência de orientação profissional e a influência de treinadores, parentes e amigos podem também contribuir com as razões que levam a atleta à adoção de certos comportamentos alimentares que a tornam vulnerável às deficiências nutricionais, comprometendo o desempenho. 
Dentro de cada modalidade esportiva, os padrões de treinamento e de alimentação podem variar significativamente entre os períodos não-competitivos e competitivos $25,29,31$.

Estudos monstraram que as alterações dos padrões dietéticos de fisiculturistas nos períodos não-competitivos e pré-competitivos (10-12 semanas antes do evento) $)^{32}$ parecem ocorrer de um modo muito peculiar ${ }^{7,29}$. Na tentativa de aprimorar a definição muscular para a competição, muitos fisiculturistas, em fase pré-competitiva, adotam dietas com importante déficit energético e nutricionalmente desequilibradas ${ }^{29}$. Contudo, a perda ponderal promovida por este tipo de estratégia, pode implicar em importante redução da massa muscular. Adicionalmente, a restrição dietética severa, principalmente de carboidratos, pode resultar em diminuição da força e da potência durante os treinos ${ }^{32}$. Via de regra, o padrão alimentar de fisiculturistas é caracterizado por dietas monótonas, ricas em fontes protéicas, limitada em laticínios e fontes de gordura e com pouca variedade de cereais, hortaliças e frutas ${ }^{7,29}$. A seleção de alimentos de baixo teor de sódio é prática comum entre esses atletas durante o período competitivo, com objetivo de evitar a retenção hídrica e acentuar a definição dos músculos 29,32 .

Sandoval \& Heyward 7 investigaram os padrões de seleção de alimentos de fisiculturistas, de ambos os sexos, durante os períodos não-competitivo e pré-competitivo. O estudo revelou que a dieta era caracterizada pela pouca variedade de alimentos dos diferentes grupos de alimentos, limitações que eram mais acentuadas durante o período pré-competitivo. Durante essa fase, o consumo do leite era diminuído, e somente os derivados do leite desnatado eram utilizados. A ingestão de carne vermelha ou gema de ovo era totalmente evitada sendo substituída por alimentos de baixo teor de gordura como peito de frango sem pele, atum em água e claras de ovos. Grãos integrais e enriquecidos, feijões secos, tubérculos, hortaliças e frutas frescas, como banana, frutas cítricas, brócolis e tomate figuravam entre as escolhas de alimentos de origem vegetal. Em atletas do sexo masculino, as reduções adicionais na seleção de alimentos durante o período pré-competitivo, envolviam os grupos do leite, hortaliças, carne e gordura.

Contrariamente às dietas extremamente hipoenergéticas, a inclusão de trabalhos aeróbios no programa de treinamento de fisiculturistas parece favorecer o alcance dos objetivos de gordura corporal, de forma mais rápida e vantajosa ${ }^{33,34}$ Foi demonstrado que, com adequado consumo protéico, o balanço energético negativo poderia ser melhor tolerado quando o déficit fosse resultante do aumento da atividade física, comparado ao gerado pela diminuição da ingestão energética ${ }^{34}$. Em relato de Manore et al. ${ }^{33}$, um fisiculturista de elite conseguiu obter, com sucesso, o percentual de gordura corporal desejado para a competição, executando um programa de exercício que enfatizava tanto o metabolismo anaeróbio quanto o aeróbio, em combinação com uma dieta hiperenergética, rica em carboidratos e adequada para a maioria dos micronutrientes, com exceção de zinco e cálcio.

Em outros grupos atléticos, no entanto, as modificações nos padrões dietéticos durante as fases de treinamento e competição não foram expressivas, embora inadequações nutricionais devam ser consideradas ${ }^{25,31}$. Conforme o comentário de Nutter ${ }^{31}$ com relação a atletas mulheres, o desejo de se manter magra parece exercer maior influência nas práticas dietéticas do que as mudanças no programa de treinamento.

Hassapidou \& Manstrantoni ${ }^{25}$ investigaram as alterações na ingestão dietética de atletas gregas de diferentes modalidades, nos períodos não competitivo e competitivo. Os autores relataram que os consumos energéticos de corredoras de meio-fundo, nadadoras e bailarinas não variaram entre os períodos não-competitivo e competitivo. Em ambos os períodos estudados, a maioria das atletas encontrava-se em balanço energético negativo, com exceção das jogadoras de voleibol durante o período competitivo. Nos dois períodos analisados, as médias do consumo energético por quilograma de peso corporal foram inferiores ao recomendado para atletas mulheres ${ }^{11}$ em todas as modalidades avaliadas (Anexo). Em 
ambos os períodos, o consumo de carboidrato foi igualmente abaixo do recomendado em todos os grupos estudados. Embora as médias de ingestões diárias de proteína tenham variado de $13,2 \%$ a $16,7 \%$, esses percentuais encontravam-se dentro das recomendações protéicas para atletas ${ }^{1}$ apenas para as corredoras e bailarinas, durante o período não-competitivo, e para as nadadoras, nos períodos não-competitivo e competitivo. Por outro lado o consumo de lipídios foi significativamente elevado em todos os grupos avaliados. Apesar do baixo consumo energético, as atletas apresentaram adequadas ingestões de micronutrientes, exceto para o ferro. Conforme as autoras, esse fato pode estar associado ao alto consumo de vegetais e frutas, padrão típico da dieta Mediterrânea.

Na comparação das dietas do período não-competitivo e competitivo de ultramaratonistas homens e mulheres, Singh et al. ${ }^{22}$ não encontraram diferenças significativas no consumo energético entre os dois períodos avaliados. No entanto, o consumo de energia foi inadequado ${ }^{11}$ tanto no período não-competitivo quanto no competitivo. Além disso, ainda que a ingestão de carboidrato tenha sido maior no período competitivo comparado ao não-competitivo, o consumo desse nutriente foi abaixo do recomendado ${ }^{1,13} \mathrm{em}$ ambas as ocasiões (Anexo). A ingestão de álcool foi significativamente mais baixa no período competitivo. Os resultados desse estudo sugerem que, embora muitos atletas procurem modificar seus padrões dietéticos em períodos pré-competitivos, a fim de favorecer seu desempenho na prova, nem sempre essa estratégia resulta na melhora de seu perfil dietético, principalmente com relação ao consumo de carboidrato. Isso reforça a importância da orientação profissional no manejo dietético em todos os períodos do treinamento.

\section{G A STO ENERGÉTICO VERSUS CONSUMO ENERGÉ TI CO: LIMITACOOES DOS MÉTODOS DE A V A LI A ÇÃO}

Diversas pesquisas relacionadas ao consumo alimentar em grupos atléticos sugerem que muitos desses indivíduos encontram-se em constante déficit energético ${ }^{6,24,30}$. As discrepâncias entre o consumo energético relatado e o dispêndio energético estimado têm sido também relacionadas às fontes de erros das metodologias empregadas nos estudos $25,26-28$.

O Anexo mostra que o método do registro dietético tem sido bastante utilizado nos estudos do consumo alimentar de atletas. A precisão das informações obtidas a partir de registros dietéticos pode ser comprometida pela dificuldade na quantificação dos alimentos e inibições associadas à auto-imagem ${ }^{6,35}$. A omissão de alimentos consumidos (sub-relato) tem sido apontada como uma das principais limitações em estudos dietéticos em atletas, embora existam referências de sobre-relatos $6,8,26$.

Em diversos estudos, as diferenças encontradas entre o consumo e o dispêndio energético diário, têm apontado para o balanço energético negativo de atletas $\varsigma^{6,25,27,30}$. Entretanto, embora a constatação, em algumas pesquisas, de tendência à redução de peso corporal dos atletas, essa perda pode não ser grande o suficiente para explicar a magnitude do déficit energético ${ }^{25,26}$, sugerindo a ocorrência concomitante de sub-relato e consumo energético insuficiente ${ }^{35}$. Em estudo com remadoras de elite, Hill \& Davies ${ }^{26}$ compararam a ingestão energética (estimada por meio de registro dietético de quatro dias com pesagem) com o dispêndio energético (estimado pelo método da água duplamente marcada). Após o reajuste do dispêndio energético para as mudanças no peso corporal, foi observado um sub-relato de menos $1133 \mathrm{kcal}$ na ingestão energética. Por outro lado, acompanhando jogadores de basquete, Leinus \& Ööpik ${ }^{27}$ identificaram importantes déficits no consumo energético, porém não detectaram significativas alterações no peso corporal. Neste estudo, a ingestão energética foi calculada a partir de registros dietéticos de quatro dias, e o gasto energético foi estimado a partir dos registros de atividades físicas e tabelas de equivalentes energéticos. As correlações positivas verificadas entre a ingestão energética, o peso corporal e o dispên- 
dio energético, sugeriram que as divergências entre a ingestão real de alimentos e o consumo registrado podem não ter sido tão acentuadas.

De modo similar à avaliação do consumo energético pelo registro alimentar, a precisão da estimativa do gasto energético de atletas por meio de registro de atividades físicas, pode também ser influenciada por sub ou sobre-relatos ${ }^{23,27}$. No registro de atividade física, o atleta deverá detalhar a qualidade e quantidade (tipo, tempo despendido, distância percorrida etc.) de todas as suas atividades físicas diárias (treinamento e recreação) 23,24. Outras informações específicas relativas à qualidade do treinamento (velocidade, freqüência cardíaca, percepção de esforço e outros) podem também ser requeridas ${ }^{24}$. Essas informações, de modo similar aos registros dietéticos, estão sujeitas a erros, podendo ocorrer os sub-relatos, baixo consumo energético e superestimativa do dispêndio energético.

Recentemente, a determinação do dispêndio energético por meio de isótopos vem sendo descrita como padrão ouro na validação do consumo energético avaliado por auto-relato, assim como, na estimativa do gasto energético de atletas. Pesquisas que empregaram o método da água duplamente marcada têm ressaltado as discrepâncias que podem ser detectadas entre o gasto energético estimado e a ingestão energética avaliada por registros dietéticos ${ }^{26,28}$. Entretanto, o custo elevado desse procedimento limita o seu uso. Ebine et al. ${ }^{28}$ comparam o gasto energético de jogadores de futebol profissionais, obtidos pelo método da água duplamente marcada, àquele calculado por meio de registro dietético de sete dias. Visto que não foram detectadas modificações significativas no peso corporal dos atletas, a diferença encontrada entre os métodos (menos $419 \mathrm{kcal}$ ) foi atribuída a sub-relatos.

A realização de estudos de validação de métodos de avaliação dietética por auto-relato, em diferentes grupos atléticos, assim como o rigor metodológico na aplicação desses instrumentos, talvez possa auxiliar na identificação e no controle de erros sistemáticos típicos destas populações.

\section{O N C L U S Ã O}

As relações entre o comportamento alimentar e as alterações fisiológicas e metabólicas em atletas têm despertado a atenção de diversos autores na última década. Infelizmente, embora as recomendações já tenham sido estabelecidas, os resultados de recentes estudos revelam que a inadequação nutricional ainda predomina em vários grupos atléticos. Isso demonstra que a prática alimentar e dietética dessa população ainda permanece distante das recomendações. Em diferentes modalidades esportivas, muitos atletas, especialmente do sexo feminino, procuram na restrição dietética um meio de adequar o peso corporal e otimizar o rendimento no exercício. Paradoxalmente, os padrões de alimentação delineados nesses grupos têm envolvido um consumo limitado de importantes nutrientes estreitamente associados ao desempenho esportivo.

Em vista de freqüentes variações no padrão alimentar de atletas, em função de aspectos relacionados ao treinamento, o método do registro dietético parece ser o instrumento mais utilizado na avaliação do consumo alimentar destes indivíduos. Entretanto, a grande possibilidade da ocorrência de erros sistemáticos parece ressaltar, ainda mais, a importância do rigor metodológico em pesquisas que utilizam métodos baseados no auto-relato nesta população.

De uma forma geral, os estudos têm reafirmado a necessidade da reeducação nutricional em diferentes grupos atléticos. Contudo, a percepção prática tem alertado para a compreensão de que o satisfatório atendimento das demandas nutricionais de atletas requer a elaboração de um cuidadoso planejamento alimentar, que inclua manipulações dietéticas adaptadas à sua modalidade esportiva e estilo de vida. Afinal, são inúmeros fatores, e não somente a falta de conhecimentos sobre nutrição, que podem, expressivamente, influenciar o padrão alimentar típico de um grupo atlético e, conseqüentemente, a sua performance e saúde. 


\section{COLABORADORES}

V.P. PANZA liderou o delineamento, a revisão da literatura e a redação do artigo. M.S.P.H. COELHO participou do delineamento, revisão da literatura e redação do artigo. M.A.A. Assis, P.F. Di PIETRO e F.A.G. VASCONCELOS orientaram a revisão da literatura e a redação do artigo. Todos os autores contribuíram substancialmente na correção da primeira versão e redação da versão final.

\section{REFERÊ NCIAS}

1. American Dietetic Association, Dietitians of Canada, American College of Sports Medicine. Position of American Dietitic Association, Dietitians of Canada, and American College of Sports Medicine: nutritrion and athletic performance. J Am Diet Assoc. 2001; 100(12):1543-56.

2. Lukaski HC. Vitamin and mineral status: effects on physical performance. Nutrition. 2004; 20(7-8): 632-44

3. Thong FSL, McLean C, Graham TE. Plasma leptin in female athletes: relationship with body fat reproductive, nutritional, and endocrine factors. J Appl Physiol. 2000; 88(6):2037-44

4. Nieman DC, Henson DA, Smith LL, Utter AC, Vinci DM, Davis JM, et al. Cytokine changes after a marathon race. Appl Physiol. 2001; 91(1):109-14.

5. Burke LM, Gollan RA, Read RSD. Dietary intakes and food use of groups of elite australian male athletes. Int J Sport Nutr. 1991; 1(4):378-94.

6. Ziegler PJ, Jonnalagadda SJ, Lawrence C. Dietary intake of elite figure skating dancers. Nutr Res. 2001; 21(7):983-92.

7. Sandoval WM, Heyward VH. Food selection patterns of bodybuilders. Int J Sport Nutr. 1991; $1(1): 61-8$

8. Mullinix MC, Jonnalagadda SJ, Rosenbloom CA Thompson WR, Kicklighter JR. Dietary intake of female US soccer players. Nutr Res. 2003; 23(5): 585-93.

9. Paschoal VC, Amancio OM. Nutritional status of Brazilian elite swimmers. Int J Sport Nutr Exerc Metab. 2004; 14(1):81-94.

10. Ziegler PJ, Jonnalagadda SJ, Nelson JA, Lawrence C, Baciak B. Contribution of meals and snacks to nutrient intake of male and female elite figure skaters during peak competitive season. J Am Coll Nutr. 2002; 21(2):114-9.
11. Economos CD, Bortz SS, Nelson ME. Nutritional practices of elite athletes. Pratical recommendations. Sports Med. 1993; 16(6):381-99.

12. Achten J, Halson, SL, Moseley L, Rayson MP, Casey A, Jeukendrup AE. Higher dietary carbohydrate content during intensified running training results in better maintenance of performance and mood state. J Appl Physiol. 2004; 96(4):1331-40.

13. Applegate EA. Nutritional considerations for ultraendurance performance. Int J Sport Nutr. $1991 ; 1(2): 118-26$

14. Tarnopolsky MA. Protein requirements for endurance athletes. Nutrition. 2004; 20(7-8): 662-8.

15. Phillips SM. Protein requirements and supplementaion for strength sports. Nutrition. 2004; 20(7-8): 689-95.

16. Dorgan JF, Judd JT, Longcope C, Brown C, Schatzkin A, Clevidence BA, et al. Effects of dietary fat and fiber on plasma and urine androgens and estrogens in men: a controlled feeding study. Am J Clin Nutr. 1996; 4(6):850-5.

17. Mickleborough TD, Murray RL, Ionescu AA, Lindley MR. Fish oil supplementation reduces severity of exercise-induced bronchoconstriction in elite athletes. Am J Respir Crit Care Med. 2003; 168(10): 1181-9.

18. Storlie J. Nutrition assessment of athletes: a model for integrating nutrition and physical performance indicators. Int J Sport Nutr. 1991; 1:192-204.

19. Manore MM. Effect of physical activity on thiamine, riboflavine, and vitamin B-6 requirements. Am J Clin Nutr. 2000; 72(Suppl):598-606.

20. Institute of Medicine of the National Academies (US). Food and nutrition board. Dietary reference intakes tables: the complete set. Washington (DC): The National Academies; 2005 [cited 2005 Aug 2]. Available from: http://www.iom.edu/board. asp? id=3788

21. Sawka MN. Physiological consequenses of hypohydration: exercise performance and termoregulation. Med Sci Sports Exerc. 1992; 24(6): 657-70.

22. Singh A, Evans P, Gallagher KL, Deuster PA. Dietary intakes and biochemical profiles of nutritional status of ultramarathoners. Med Sci Sports Exerc. 1993; 25(3):328-34

23. Christensen DL, van Hall G, Hambraeus L. Food and macronutrient intake of male adolescent Kalenjin runners in Kenya. Br J Nutr. 2002; 88(6): 711-17.

24. Beals KA. Eating behaviors, nutritional status, and menstrual function in elite female adolescent 
volleyball players. J Am Diet Assoc. 2002; 102(9): 1293-6.

25. Hassapidou MN, Manstrantoni A. Dietary intakes of elite female athletes in Greece. J Hum Nutr Diet. 2001; 14(5):391-6.

26. Hill RJ, Davies PSW. Energy intake and energy expenditure in elite lightweight female rowers. Med Sci Sports Exerc. 2002: 34(11):1823-29.

27. Leinus K, Ööpick V. Habitual nutrient intake and energy expenditure of students participating in recreational sports. Nutr Res. 1998; 18(4): 683-91.

28. Ebine N, Rafamantanantsoa HH, Nayuky $Y$, Yamanaka K, Tshima K, Ono T, et al. Measurement of total energy expenditure by the doubly labelled water method in professional soccer players. J Sport Sci. 2002; 20(5):391-7.

29. Steen SN. Precontest strategies of a male bodybuilder. Int J Sport Nutr. 1991; 1(1):69-78.

30. Ziegler P, Nelson JA, Barratt-Fornell A, Fiveash L, Drewnowski A. Energy and macronutrient intakes of elite figure skaters. J Am Diet Assoc. 2001; 101(3):319-25.

31. Nutter J. Seasonal changes in female athletes' diets. Int J Sport Nutr. 1991; 1(4):395-407.

32. Kleiner SM, Greenwood-Robinson M. Nutrição para o treinamento de força. São Paulo: Manole; 2002.

33. Manore MM, Thompson J, Russo M. Diet and exercise strategies of a world-class bodybuilder. Int J Sport Nutr. 1993; 3(1):76-86.

34. Todd KS, Butterfield GE, Calloway DH. Nitrogen balance in men with adequate and deficient energy intake at three levels of work. J Nutr. 1984; 114(11): 2107-18.

35. Hill RJ, Davies PSW. The validity of self-reported energy intake as determined using the doubly labelled water technique. Br J Nutr. 2001; 85(4): 415-30.

Recebido em: 16/12/2005

Versão final reapresentada em: 21/12/2006 Aprovado em: 6/9/2007 
$692 \mid$ V.P. PANZA et al.

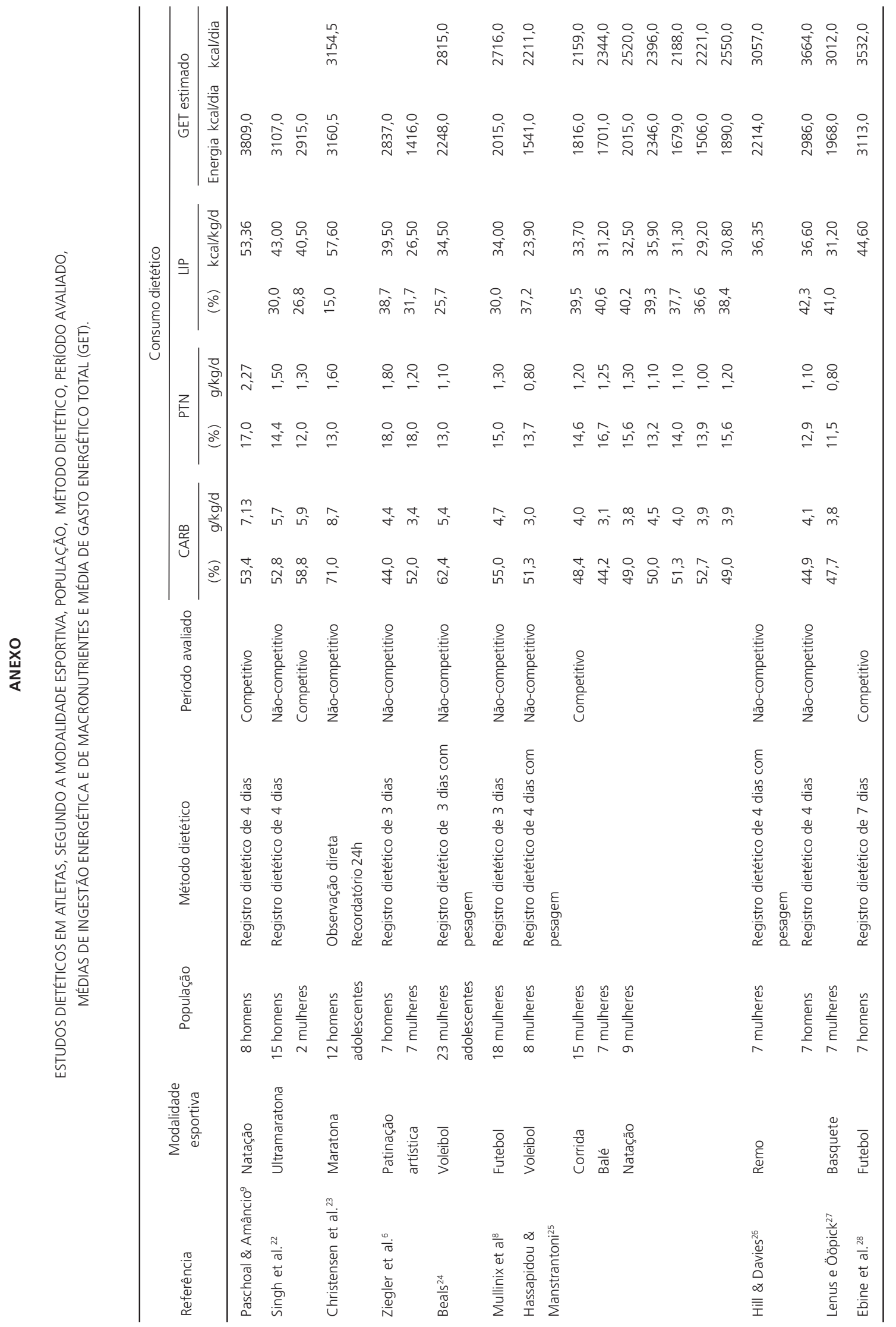

